UDC 502.131:658.011.8

LBC 20.1

\title{
IMPROVING THE ECOLOGICALAND ECONOMIC INDICES OF THE COMPANY ON THE BASIS OF THE BEST AVAILABLE TECHNIQUES
}

\author{
Anna G. Gunkova \\ Samara State Transport University, Samara, Russian Federation \\ Yuriy A. Kholopov \\ Samara State Transport University, Samara, Russian Federation
}

\begin{abstract}
It is shown that the modern society pays much attention to the issue of environmental security. On the basis of literary sources it is noted that there is a trend to strengthening the role of environmentally oriented management methods, guidelines for the modernization of production, implementation of environmental management systems and environmental certification. Environmental certification helps the company to properly allocate resources for environmental protection and provides the state with the accurate data and the receipt of payments in budgets of all levels for negative impact on the environment. The structural changes are based on the requirements of the environmental legislation, new requirements to ecological regulation. The authors confirm the need for transition to the Best available techniques (BAT), which significantly improve environmental and economic performance of the enterprise. Implementation of BAT requires the effective replacement of obsolete resource-intensive production and modern technology. Such transitions affect the size of payments for negative impact on the environment and the volume of economic incentives from the state. It is noted that Russia applies the European experience as a basis of creating guidebooks on the best available techniques. The definition of technology as the best available techniques is determined by the resolution of the Government of the Russian Federation. Indicators and information generated in the BREF are also required in carrying out the environmental monitoring and control. Changes in these indicators reflect the quality of the technology used. Implementation of BAT requires significant investments, the priority should be conservation projects that eliminate the most acute environmental problems and maximize environmental benefits. The increased interest of enterprises in the application of environmental technologies is not only based on obtaining favorable conditions for state support, but are also aimed at improving the company's image, increasing economic capacity and competitiveness.

Key words: the best available techniques, environment-oriented legislation, negative impact, ecological security, environmental policy, green economy, environmental management, environmental monitoring, catalogs of the best available techniques.
\end{abstract}

УДК 502.131:658.011.8

ББК 20.1

УЛУЧШЕНИЕ ЭКОЛОГО-ЭКОНОМИЧЕСКИХ ПОКАЗАТЕЛЕЙ
ПРЕДПРИЯТИЯ НА ОСНОВЕ ВНЕДРЕНИЯ
НАИЛУЧШИХ ДОСТУПНЫХ ТЕХНОЛОГИЙ

\author{
Анна Геннадьевна Гунькова \\ Самарский государственный университет путей сообщения, г. Самара, Российская Федерация \\ Юрий Александрович Холопов \\ Самарский государственный университет путей сообщения, г. Самара, Российская Федерация
}

Аннотация. Показано, что в современном обществе вопросу экологической безопасности уделяется большое внимание. На основе литературных источников отмечается тенденция к усилению роли экологи- 


\section{ЗАРУБЕЖНЫЙ ОПЫТ НАДНАЦИОНАЛЬНОГО РЕГУЛИРОВАНИЯ}

чески ориентированных методов управления, ориентиров на модернизацию производства, внедрению систем экологического менеджмента и экологической сертификации. Экологическая сертификация помогает предприятию правильно распределить ресурсы на природоохранные мероприятия, а государству обеспечивает достоверность данных и поступление платежей за негативное воздействие на окружающую среду в бюджеты всех уровней. В основе структурных изменений лежат требования природоохранного законодательства, новые требования к экологическому нормированию. Подтверждена необходимость перехода на наилучшие доступные технологии (НДТ), что значительно улучшает эколого-экономические показатели предприятия. Внедрение НДТ предполагает эффективную замену устаревших ресурсоемких производств и технологий современными. Такие переходы влияют на размер платы за негативное воздействие на окружающую среду и объемы экономического стимулирования со стороны государства. Отмечено, что в России взят за основу европейский опыт по созданию справочников наилучших доступных технологий. Порядок определения технологии в качестве наилучшей доступной технологии определен постановлением Правительства РФ. Показатели и сведения, сформированные в справочнике по НДТ, также необходимы при проведении экологического мониторинга и контроля. По изменениям данных показателей можно судить о качестве используемых технологий. Внедрение НДТ требует значительных инвестиций, в приоритете должны быть природоохранные проекты, позволяющие ликвидировать самые острые экологические проблемы и дающие максимальный экологический эффект. Возросший интерес предприятий к применению экологических технологий основывается не только на получении выгодных условий государственной поддержки, но и направлен на повышение имиджа компании, повышение экономического потенциала и конкурентоспособности.

Ключевые слова: наилучшие доступные технологии, природоохранное законодательство, негативное воздействие, экологическая безопасность, экологическая политика, «зеленая» экономика, экологический менеджмент, экологический мониторинг, справочники НДТ.

В современном обществе вопросу экологической безопасности уделяется большое внимание. В противовес антиэкологичной модели «коричневой» экономики в мире и отдельных странах инициируется выработка нового «зеленого» экономического курса, ориентированного на модернизацию, технологическое обновление, инновации и инвестиции в «зеленый» бизнес, технологии, энергосбережение и т. п. [2, с. 5].

Очевидно, что содержанием федеральной политики в области экологического развития страны должна быть стратегия «зеленого» роста, которая предусматривает интеграцию социально-экономического и экологического развития в виде «зеленой» экономики [10, с. 108]. По мнению Е.А. Иванцовой, В.А. Кузьмина [6, с. 140], отмечается возрастание роли экономической науки в формировании и развитии экологической политики.

Современные экологически ориентированные методы управления должны стимулировать снижение ресурсоемкости и повышение энергоэффективности хозяйственной деятельности, использование возобновляемых и вторичных ресурсов [7, с. 236].

Сегодня клиенты, участвующие в международных сделках, банки и страховые компании все чаще стали требовать сертификацию сис- тем экологического менеджмента на соответствие требованиям стандарта ISO 14001 в качестве доказательства, что организации можно доверять в области экологической деятельности $[1$, с. 59].

Проведение экологической сертификации, с одной стороны, помогает предприятию правильно распределить ресурсы на природоохранные мероприятия, с другой - обеспечивает государству достоверность данных и поступление платежей за негативное воздействие на окружающую среду в бюджеты всех уровней.

В целом процесс экологизации должен основываться на эффективном взаимодействии государства, бизнеса и общества [3, с. 76].

В связи с внесением изменений на законодательном уровне [13] с 1 января 2015 г. устанавливаются новые требования к экологическому нормированию. В их основу положены технологические нормативы. В рамках проведенных реформ предприятиям, ведущим хозяйственную деятельность, необходимо оперативно внедрять наилучшие доступные технологии (НДТ).

Прежде в большинстве нормативных документов использовался термин «наилучшие существующие технологии - НСТ», но с 2015 г. было введено определение: «наилуч- 
шая доступная технология - технология производства продукции (товаров), выполнения работ, оказания услуг, определяемая на основе современных достижений науки и техники и наилучшего сочетания критериев достижения целей охраны окружающей среды при условии наличия технической возможности ее применения» [13].

Из истории возникновения сочетания «наилучшие доступные технологии» можно отметить, что впервые данный термин был использован в 1984 г. в Европе в директиве рабочей группы по атмосферному воздуху (Air Frame work Directive - AFD) и имел отношение к выбросам крупных промышленных предприятий, загрязняющим атмосферный воздух. В последующие годы формулировка данной директивы была модифицирована и вместе с другими предписаниями, регулирующими большие промышленные объекты, вошла в состав Директивы промышленных выбросов. На основании этого документа были разработаны и утверждены отраслевые справочники наилучших существующих технологий BREF [19].

Внедрение НДТ предполагает эффективную замену устаревших ресурсоемких производств и технологий современными. Такие переходы влияют на размер платы за негативное воздействие на окружающую среду и объемы экономического стимулирования со стороны государства. В основе применения наилучших доступных технологий лежит нормирование экологически опасных предприятий. Понятие «наилучшие технологии» можно охарактеризовать как процесс или способ, с использованием которого осуществляется наиболее эффективное достижение высокого уровня защиты окружающей среды в целом. К доступным относятся только те технологии, в которых учтены экологические, экономические и производственные условия, что делает возможным их внедрение уже в настоящее время.

Вступление России во Всемирную торговую организацию, произошедшее в августе 2012 г., в ближайшем будущем потребует от предприятий приведения технологии производства и выпускаемой продукции в соответствие с требованиями международных экологических стандартов. Конкурентоспособные пред- приятия будут вынуждены в сжатые сроки модернизировать производство [8, с. 21].

Сравнивая практику внедрения НДТ в Европе и России, можно отметить, что на данный момент в европейских странах ведется разработка справочников НДТ на международном уровне совместно с промышленными предприятиями. Данная деятельность предполагает применение НДТ как в одной конкретной отрасли промышленности, так и в большинстве отраслей. Особенностью российских предприятий является сильная изношенность основных фондов, использование устаревшего оборудования, поэтому при наличии свободных средств или инвестиций бывает выгоднее не пытаться присоединять к старым технологическим циклам очистные сооружения, фильтры и т. п., а сразу делать технологический прорыв.

Для экологизации предприятий природоохранным законодательством предусмотрено введение разного вида льгот. В счет платы за негативное воздействие будут включены затраты по внедрению НДТ. С тех предприятий, которые перешли на использование НДТ, плата взиматься не будет. Также будут предоставлены и налоговые льготы. Для стимулирования переходов предприятий на НДТ предлагается использовать, наряду с правовыми рычагами воздействия, экономические. Предусмотрено поэтапное повышение коэффициентов, применяющихся к ставкам платы за выбросы, сбросы и размещение отходов с превышением установленных нормативов. Размеры платы за негативное воздействие на окружающую среду должны стать сопоставимы с затратами, необходимыми для предотвращения такого воздействия.

Для сбора необходимой информации установлены требования к производственному экологическому контролю. Данные, получаемые на предприятиях, должны оперативно обрабатываться и пополнять государственный фонд данных экологического мониторинга. В целях оперативного реагирования при высоком уровне загрязнения окружающей среды предприятие обязано оснастить крупные источники выбросов автоматическими датчиками измерения и средствами передачи этой информации.

Утвержденный перечень областей использования таких технологий включает в 


\section{ЗАРУБЕЖНЫЙ ОПЫТ НАДНАЦИОНАЛЬНОГО РЕГУЛИРОВАНИЯ}

себя два раздела. В первом разделе указана любая деятельность, оказывающая сильно негативное воздействие на окружающую среду. Ко второму разделу относятся технологические процессы, оборудование, технические методы и способы, которые применяются в хозяйственной деятельности.

Для создания НДТ необходимо проанализировать уже имеющийся опыт внедрения способов и процессов в западных странах, а также создать мероприятия по регулированию и взаимодействию с основной деятельностью предприятия. Однако прямое использование (копирование) европейских справочников НДТ (BREF) невозможно [17, с. 20].

Порядок определения технологии в качестве наилучшей доступной технологии определен постановлением Правительства РФ [14].

С учетом перечня областей применения наилучших доступных технологий разрабатываются справочники НДТ. Основой для актуализации действующих справочников являются:

- информация по новым технологиям, технологическому оборудованию, экономическим и экологическим показателям, применяемым в отрасли промышленности;

- результаты законченных научно-исследовательских работ, анализа, изучения и обобщения отечественного и зарубежного опыта [14].

Такие заключения могут быть получены от промышленных предприятий и ассоциаций, федеральных органов исполнительной власти, научных и экспертных организаций.

Распоряжением Правительства РФ [15] предусмотрено создать в 2015-2017 гг. 47 справочников наилучших доступных технологий (справочники НДТ). Предполагается, что за основу и аналог абсолютного большинства этих справочников должны и будут взяты справочники BREF [19], разработанные и используемые Евросоюзом.

Показатели и сведения, сформированные в справочнике по наилучшим доступным технологиям, также необходимы при проведении экологического мониторинга и контроля. По изменениям данных показателей можно судить о качестве используемых технологий.

Привязка экологических стандартов к НДТ имеет основной положительный эффект: модернизация производства однозначно включает природоохранные мероприятия. В ряде случаев, наоборот, необходимость во внедрении НДТ в соответствии с программой экологической ответственности бизнеса и стандартами ISO14000 толкает организацию на модернизацию производства [9, с. 3560].

Возросший интерес предприятий к применению экологических технологий основывается не только на получении выгодных условий государственной поддержки, но и направлен на повышение имиджа компании, повышение экономического потенциала и конкурентоспособности.

В России НДТ начинают применяться в различных отраслях промышленности. Например, в ОАО «Газпром» разработан реестр наилучших доступных технологий, обеспечивающих экологически безопасную добычу, транспортировку, хранение и переработку углеводородного сырья, в котором по каждому рассмотренному производственному процессу и технологии составлена инвентарная карта (см. табл. 1) и установлены технологические показатели технологий $[17$, с. 20$]$.

В целлюлозно-бумажной промышленности была разработана отраслевая система технологического нормирования выбросов и размещения отходов, основанная на внедрении наилучших существующих технических средств с максимальным учетом российских реалий. Крупнейшая компания по производству алюминия утвердила экологическую стратегию и заключила договоры с научноисследовательскими институтами для разработки материалов, методик, инструкций, создания баз данных по расходным коэффициентам, качеству сырья, удельным выбросам производства с целью разработки и утверждения технологических нормативов. Большой опыт есть в энергетической и нефтегазовой отрасли. Реализация экологической политики позволила внедрить на корпоративном уровне экономические механизмы, нацеленные на внедрение наилучших доступных технологий [11].

По данным отчета Министерства промышленности и торговли «О финансовых механизмах внедрения наилучших доступных технологий в России» был проведен анализ и дана оценка необходимых инвестиций для перехода на НДТ в разрезе отраслей промышленности (см. табл. 2) [16]. 
Инвентарная карта технологии (метода, процесса)

\begin{tabular}{|c|c|}
\hline \multicolumn{2}{|r|}{ Вид деятельности (указать) } \\
\hline Показатели & Содержание \\
\hline $\begin{array}{lr}\text { Описание } & \text { технологии и } \\
\text { методов } & \text { реализации } \\
\text { процесса } & \end{array}$ & $\begin{array}{l}\text { Краткое техническое описание технологии и методов реализации процесса. Схе- } \\
\text { мы. Экологические проблемы и неблагоприятные последствия для компонентов } \\
\text { окружающей среды, связанные с применением технологий и методов. Способы } \\
\text { решения экологических проблем или предотвращения/снижения неблагоприят- } \\
\text { ных последствий }\end{array}$ \\
\hline $\begin{array}{l}\text { Преимущества техноло- } \\
\text { гии }\end{array}$ & $\begin{array}{l}\text { Экологические преимущества по сравнению с другими технологиями (снижение } \\
\text { выбросов, сбросов загрязняющих веществ, объемов образования отходов, вовлече- } \\
\text { ние отходов в процесс повторного использования, снижение потребления энерги, } \\
\text { ресурсов и т. д.) }\end{array}$ \\
\hline $\begin{array}{l}\text { Экологические и экс- } \\
\text { плуатационные показа- } \\
\text { тели технологии, техно- } \\
\text { логические нормативы }\end{array}$ & $\begin{array}{l}\text { Данные по выбросам, сбросам загрязняющих веществ, образованию отходов, по- } \\
\text { треблению сырья, ресурсов и энергии. Технологические показатели }\end{array}$ \\
\hline $\begin{array}{l}\text { Условия применения } \\
\text { технологии }\end{array}$ & $\begin{array}{l}\text { Информация об особенностях эксплуатации, обслуживания и контроля технологии, } \\
\text { обеспечения безопасности и ограничения по использованию технологии, метода. } \\
\text { Локальные (географические) условия или требования, способствующие/огранич- } \\
\text { вающие применение технологии, метода }\end{array}$ \\
\hline Примеры использования & $\begin{array}{l}\text { Примеры использования технологии, метода в регионах, в России и за рубежом (не } \\
\text { менее двух) }\end{array}$ \\
\hline $\begin{array}{l}\text { Экономические показа- } \\
\text { тели }\end{array}$ & $\begin{array}{l}\text { Капитальные вложения, эксплуатационные расходы, текущие расходы природо- } \\
\text { охранного назначения, период окупаемости в текущих экономических условиях и др. }\end{array}$ \\
\hline Справочная литература & Литература для более подробного ознакомления с технологией, методом, процессом \\
\hline
\end{tabular}

Примечание. Составлено авторами.

Таблица 2

Оценка необходимых инвестиций для перехода на НДТ

\begin{tabular}{|l|c|}
\hline \multicolumn{1}{|c|}{ Вид деятельности } & $\begin{array}{c}\text { Инвестиционные } \\
\text { средства, млрд руб. }\end{array}$ \\
\hline Добыча и переработка нефти и газа & 1985 \\
\hline Химическая промышленность & 1279 \\
\hline Производство тепловой и электрической энергии & 721 \\
\hline Целлюлозно-бумажная промышленность & 378 \\
\hline Обращение с отходами & 1200 \\
\hline Растениеводство & 1004 \\
\hline Железнодорожный транспорт & 995 \\
\hline Прочие отрасли (в части эксплуатации зданий) & 2505 \\
\hline
\end{tabular}

Примечание. Составлено авторами по: [16].

В ближайшие 10-20 лет важным принципом социально-экономической политики и основой экологической политики должна стать политика «двойного выигрыша», когда экономические эффекты сопровождаются экологическими [2, с. 14].

С позиции системы экологического менеджмента в приоритете должны быть природоохранные проекты, позволяющие ликвидировать самые острые экологические проблемы и дающие максимальный экологический эффект на каждый рубль инвестиций $[4$, с. 82$]$.
При внедрении НДТ необходимо помнить, что наряду с «вертикальными» (отраслевыми) НДТ существуют еще и «горизонтальные» НДТ, в том числе - наилучшие доступные технологии очистки выбросов и сбросов, переработки отходов. В отдельных наиболее сложных случаях может потребоваться совместное внедрение «вертикальных» и «горизонтальных» НДТ [12, с. 244].

Необходимо отметить, что большая доля инвестиционных средств направлена на добычу и переработку нефти и газа, это обусловлено тем, что Россия является одним из 


\section{ЗАРУБЕЖНЫЙ ОПЫТ НАДНАЦИОНАЛЬНОГО РЕГУЛИРОВАНИЯ}

ведущих экспортеров нефтяной продукции в мире. Значительная роль в транспортировке различных (в том числе и нефтесодержащих) грузов отводится железнодорожному транспорту. В деятельности железнодорожной отрасли также прослеживается эффективное внедрение НДТ [5], несмотря на то что в соответствии с уровнем воздействия на окружающую среду данная отрасль оказывает умеренное воздействие. Предполагается, что внедрение наилучших доступных технологий на железнодорожном транспорте позволит не только улучшить экологическую обстановку, но и повлечет за собой экономический рост.

В работе [18, с. 60] отражены основные технологии, которые планируется внедрить на железной дороге. Они включают в себя технологии очистки сточных вод, снижение шумового воздействия, обезвреживание отходов производства, ресурсосберегающие технологии, технические методы и способы, использование модернизированных приборов учета водопотребления и водоотведения. Результатом их внедрения станет увеличение эффективности экономической составляющей деятельности.

Таким образом, принятие за основу европейского опыта по созданию и классификации наилучших доступных технологий не отменяет актуальности отечественных поисковых работ в этой сфере. В настоящее время ведется активная работа по мониторингу российских технологий, развитие которых позволит заменить западные аналоги. Грамотно разработанные и введенные технологии гарантируют предприятию не только снижение негативного воздействия на окружающую среду, но и повышение конкурентоспособности и экономической привлекательности.

\section{СПИСОК ЛИТЕРАТУРЫ}

1. Антропов, В. А. Экологический менеджмент в промышленности / В. А. Антропов, Е. Н. Морозова // Вестник Уральского государственного университета пугей сообщения. - 2015. - № 1 (25). C. 56-62.

2. Бобылев, С. Н. Экологические вызовы и «зеленая» экономика / С. Н. Бобылев // Вестник МИТХТ. Серия: Социально-гуманитарные науки и экология. - 2014. - Т. 1, № 1. - С. 5-14.
3. Герасимова, Е. А. Экологический менеджмент как основа эколого-ориентированного развития предприятия / Е. А. Герасимова, И. Г. Красильникова, Ю. А. Холопов // Вестник СамГУПС. 2017. - № 1 (35). - С. 76-79.

4. Гунькова, А. Г. Экологический менеджмент как инструмент повышения экономического потенциала предприятия / А. Г. Гунькова, Ю. А. Холопов // Вестник СамГУПС. - 2017. - № 1 (35). - С. 80-83.

5. Дружина, Н. А. Использование современных технологий для организации приема и очистки ливневых и талых сточных вод с территории ремонтного локомотивного депо Бугульма - Грузовая / Н. А. Дружина, В. Н. Челноков, Ю. А. Холопов // Наука и образование транспорту. - 2016. - № 2. C. $128-130$.

6. Иванцова, Е. А. Управление эколого-экономической безопасностью промышленных предприятий / Е. А. Иванцова, В. А. Кузьмин // Вестник Волгоградского государственного университета. Серия 3, Экономика. Экология. - 2014. - № 5. C. 136-146.

7. Кириллов, С. Н. Применение программноцелевых методов в решении экологических проблем / С. Н. Кириллов, А. А. Матвеева // Вестник Волгоградского государственного университета. Серия 3 , Экономика. Экология. -2013. - № 2 (23). - С. 229-238.

8. Копыльцова, С. Е. Создание информационно-справочной системы по наилучшим доступным технологиям в пищевой промышленности на основе экологической оценки жизненного цикла / С. Е. Копыльцова // Научный журнал НИУ ИТМО. Серия: Экономика и экологический менеджмент. 2013. - № 4. - С. 21.

9. Косякова, И. В. Перспективы внедрения в России стандартов наилучших доступных технологий в рамках экологического менеджмента / И. В. Косякова, О. М. Артамонова, А. В. Кудряшов // Фундаментальные исследования. - 2015. - № 2-16. C. $3559-3563$.

10. Кудинова, Г. Э. Парадигма перехода России и регионов к «зеленой экономике» и устойчивому развитию / Г. Э. Кудинова // Вестник Волгоградского государственного университета. Серия 3 , Экономика. Экология. - 2014. - № 3. - С. 104-112.

11. Лабыкин, А. С. Российская промышленность входит в «зеленую зону» / А. С. Лабыкин. Электрон. текстовые дан. - Режим доступа: http:// expert.ru/2014/11/12/rossijskaya-promyishlennostvhodit-v-zelenuyu-zonu. - Загл. с экрана.

12. Милешко, Л. П. Перспективы обеспечения экологической безопасности основных производств при помощи наилучших доступных технологий / Л. П. Милешко, О. В. Попова, Л. В. Толмачева // Технологии техносферной безопасности. -2015 . - № 6 (64). - С. 244-247. 
13. О внесении изменений в Федеральный закон от 21.07.2014 г. № 219-Ф3 «Об охране окружающей среды» и отдельные законодательные акты Российской Федерации // Российская газета. - 2014. № 6438 ((166), 25 июля).

14. О порядке определения технологии в качестве наилучшей доступной технологии, а также разработки, актуализации и опубликования информационно-технических справочников по наилучшим доступным технологиям (с изм. и доп.) : постановление Правительства РФ от 23 дек. 2014 г. № 1458. - Доступ из справ.-правовой системы «ГАРАНТ».

15. Опоэтапном графике создания в 2015-2017 гт. отраслевых справочников наилучших доступных технологий : распоряжение Правительства Российской Федерации от 31 окт. 2014 г. № 2178-р. - Доступ из справ.-правовой системы «КонсультантПлюс».

16. Отчет Министерства промышленности и торговли «О финансовых механизмах внедрения наилучших доступных технологий в России». - Электрон. текстовые дан. - Режим доступа: http://www.mnr.gov.ru. - Загл. с экрана.

17. Пыстина, Н. Б. Учет региональной специфики при выборе наилучших доступных технологий в нефтегазовом комплексе / Н. Б. Пыстина, Н. В. Попадько // Региональная экология. - 2015. № 7 (42). - С. 16-24.

18. Рябухин, Э. А. Российским железным дорогам - наилучшие доступные технологии / Э. А. Рябухин, Е. В. Ковалева // Железнодорожный транспорт. 2016. - № 9. - C. 58-61.

19. Best available techniques Reference document (BREFs) developed under the IPPC Directive and the IED // Reference documents under the IPPC Directive and the IED. - Electronic text data. Mode of access: http://eippcb.jrc.ec.europa.eu/ reference. - Title from screen.

\section{REFERENCES}

1. Antropov V.A., Morozova E.N. Ekologicheskiy menedzhment $\mathrm{v}$ promyshlennosti [Environmental Management in Industry] Vestnik Uralskogo gosudarstvennogo universiteta putey soobshcheniya [Bulletin of the Ural State University of Railway Engineering], 2015, no. 1 (25), pp. 56-62.

2. Bobylev S.N. Ekologicheskie vyzovy i «zelenaya» ekonomika [Environmental Challenges and Green Economy]. Vestnik MITKhT. Seriya: Sotsialnogumanitarnye nauki i ekologiya, 2014, vol. 1, no. 1, pp. 5-14.

3. Gerasimova E.A., Krasilnikova I.G., KholopovYu.A. Ekologicheskiy menedzhment kak osnova ekologoorientirovannogo razvitiya predpriyatiya
[Environmental Management as a Basis for Ecologically Oriented Development of the Enterprise]. Vestnik SamGUPS [Bulletin of the Samara State Transport University], 2017, no. 1 (35), pp. 76-79.

4. Gunkova A.G., Kholopov Yu.A. Ekologicheskiy menedzhment kak instrument povysheniya ekonomicheskogo potentsiala predpriyatiya [Environmental Management as a Tool to Improve the Economic Potential of the Enterprise]. Vestnik SamGUPS [Bulletin of the Samara State Transport University], 2017, no. 1 (35), pp. 80-83.

5. Druzhina N.A., Chelnokov V.N., KholopovYu.A. Ispolzovanie sovremennykh tekhnologiy dlya organizatsii priema i ochistki livnevykh i talykh stochnykh vod s territorii remontnogo lokomotivnogo depo Bugulma - Gruzovaya [The Use of Modern Technologies for Collection and Treatment of Stormwater and Snowmelt Wastewater from the Territory of the Repair of Locomotive Depot BugulmaGruzovaya]. Nauka i obrazovanie transportu, 2016, no. 2, pp. 128-130.

6. Ivantsova E.A., Kuzmin V.A. Upravlenie ekologoekonomicheskoy bezopasnostyu promyshlennykh predpriyatiy [Management of Ecological and Economic Security of Industrial Enterprises]. Vestnik Volgogradskogo gosudarstvennogo universiteta. Seriya 3, Ekonomika. Ekologiya [Science journal of Volgograd State University. Global Economic System], 2014, no. 5, pp. 136-146. DOI: http://dx.doi.org/10.15688/ jvolsu3.2014.5.14

7. Kirillov S.N., Matveeva A.A. Primenenie programmno-tselevykh metodov $\mathrm{V}$ reshenii ekologicheskikh problem [The Application of ProgramTarget Methods in the Solution of Environmental Problems]. Vestnik Volgogradskogo gosudarstvennogo universiteta. Seriya 3, Ekonomika. Ekologiya [Science journal of Volgograd State University. Global Economic System], 2013, no. 2(23), pp. 229-238.

8. Kopyltsova S.E. Sozdanie informatsionnospravochnoy sistemy po nailuchshim dostupnym tekhnologiyam $\mathrm{v}$ pishchevoy promyshlennosti na osnove ekologicheskoy otsenki zhiznennogo tsikla [Creation of a Reference System on the Best Available Technologies in the Food Industry Based on the Environmental Life Cycle Assessment]. Nauchnyy zhurnal NIU ITMO. Seriya: Ekonomika $i$ ekologicheskiy menedzhment, 2013, no. 4, p. 21.

9. Kosyakova I.V., Artamonova O.M., Kudryashov A.V. Perspektivy vnedreniya v Rossii standartov nailuchshikh dostupnykh tekhnologiy $\mathrm{v}$ ramkakh ekologicheskogo menedzhmenta [Prospects for the Standards for the Best Available Technologies Introduction in Russia within the Framework of Environmental Management]. Fundamentalnye issledovaniya [Fundamental Research], 2015, no. 216, pp. 3559-3563. 


\section{ЗАРУБЕЖНЫЙ ОПЫТ НАДНАЦИОНАЛЬНОГО РЕГУЛИРОВАНИЯ}

10. Kudinova G.E. Paradigma perekhoda Rossii i regionov $\mathrm{k}$ «zelenoy ekonomike» $\mathrm{i}$ ustoychivomu razvitiyu [Paradigm of Russia's Transition to Green Economy and Sustainable Development]. Vestnik Volgogradskogo gosudarstvennogo universiteta. Seriya 3, Ekonomika. Ekologiya [Science journal of Volgograd State University. Global Economic System], 2014, no. 3, pp. 104-112. DOI: http://dx.doi.org/ 10.15688/jvolsu3.2014.3.11.

11. Labykin A.S. Rossiyskaya promyshlennost vkhodit v «zelenuyu zonu» [Russian Industry Enters the "Green Zone"]. URL: http://expert.ru/2014/11/12/ rossijskaya-promyishlennost-vhodit-v-zelenuyu-zonu/.

12. Mileshko L.P., Popova O.V., Tolmacheva L.V. Perspektivy obespecheniya ekologicheskoy bezopasnosti osnovnykh proizvodstv pri pomoshchi nailuchshikh dostupnykh tekhnologiy [Perspectives of Environmental Security of Major Industries Using the Best Available Technologies]. Tekhnologii tekhnosfernoy bezopasnosti, 2015, no. 6(64), pp. 244-247.

13. O vnesenii izmeneniy v Federalnyy zakon ot 21.07.2014 g. № 219-FZ «Ob okhrane okruzhayushchey sredy» i otdelnye zakonodatelnye akty Rossiyskoy Federatsii [On Amending the Federal Law of July 21, 2014 no. 219-FL “On Environmental Protection” and Certain Legal Acts of the Russian Federation Federal Law]. Rossiyskaya gazeta, 2014, no. 6438 (166), July 25, 2014.

14. O poryadke opredeleniya tekhnologii $v$ kachestve nailuchshey dostupnoy tekhnologii, a takzhe razrabotki, aktualizatsii $i$ opublikovaniya informatsionno-tekhnicheskikh spravochnikov po nailuchshim dostupnym tekhnologiyam (s izm. $i$ dop.): postanovlenie Pravitelstva RF ot 23 dek. 2014 g. № 1458 [About Identifying Technology Procedure as the Best Available Technology, as Well as Developing, Updating and Publishing Information and Technical Reference Books on the Best Available Technologies: Decree of the Government of the Russian Federation of December 23, 2014 no. 1458]. Access from Reference Legal System "GARANT".

15. O poetapnom grafike sozdaniya $v 2015-$ 2017 gg. otraslevykh spravochnikov nailuchshikh dostupnykh tekhnologiy: rasporyazhenie Pravitelstva Rossiyskoy Federatsii ot 31 okt. 2014 g. № 2178-r [About the Phased Schedule for the Industry Directories of the Best Available Technologies Creation in 20152017: Decree of the Government of the Russian Federation of October 31, 2014 no. 2178-r]. Access from Reference Legal System "KonsultantPlyus".

16. Otchet Ministerstva promyshlennosti $i$ torgovli «O finansovykh mekhanizmakh vnedreniya nailuchshikh dostupnykh tekhnologiy $v$ Rossii» [The Report of the Ministry of Industry and Trade "On Financial Mechanisms for the Implementation of the Best Available Technologies in Russia"]. URL: http:// www.mnr.gov.ru.

17. Pystina N.B., Popadko N.V. Uchet regionalnoy spetsifiki pri vybore nailuchshikh dostupnykh tekhnologiy v neftegazovom komplekse [Accounting of Regional Specificities When Selecting the Best Available Technologies in the Oil and Gas Industry]. Regionalnaya ekologiya, 2015, no. 7 (42), pp. 16-24.

18. Ryabukhin E.A., Kovaleva E.V. Rossiyskim zheleznym dorogam - nailuchshie dostupnye tekhnologii [The Best Available Technologies for Russian Railways]. Zheleznodorozhnyy transport, 2016, no. 9, pp. 58-61.

19. Best available techniques Reference document (BREFs) developed under the IPPC Directive and the IED. Reference documents under the IPPC Directive and the IED. URL: http:// eippcb.jrc.ec.europa.eu/reference/.

\section{Information about the Authors}

Anna G. Gunkova, Postgraduate Student, Samara State Transport University, Svobody St., 2V, 443066 Samara, Russian Federation, anna19rezukova@mail.ru.

Yuriy A. Kholopov, Candidate of Sciences (Agriculture), Associate Professor, Department of Construction, Samara State Transport University, Svobody St., 2V, 443066 Samara, Russian Federation, kholopov@bk.ru.

\section{Информация об авторах}

Анна Геннадьевна Гунькова, аспирант, Самарский государственный университет путей сообщения, ул. Свободы, 2B, 443066 г. Самара, Российская Федерация, anna19rezukova@mail.ru.

Юрий Александрович Холопов, кандидат сельскохозяйственных наук, доцент кафедры строительства, Самарский государственный университет путей сообщения, ул. Свободы, 2В, 443066 г. Самара, Российская Федерация, kholopov@bk.ru. 